\title{
Observed Changes in the Lifetime and Amplitude of the Madden-Julian Oscillation Associated with Interannual ENSO Sea Surface Temperature Anomalies
}

\author{
BENJAMIN POHL \\ Centre de Recherches de Climatologie, CNRS/Université de Bourgogne, Dijon, France
}

AdRian J. MatTHEWs

Schools of Environmental Sciences and Mathematics, University of East Anglia, Norwich, United Kingdom

(Manuscript received 8 May 2006, in final form 9 January 2007)

\begin{abstract}
The Madden-Julian oscillation (MJO) is analyzed using the reanalysis zonal wind- and satellite outgoing longwave radiation-based indices of Wheeler and Hendon for the 1974-2005 period. The average lifetime of the MJO events varies with season (36 days for events whose central date occurs in December, and 48 days for events in September). The lifetime of the MJO in the equinoctial seasons (March-May and October-December) is also dependent on the state of El Niño-Southern Oscillation (ENSO). During October-December it is only 32 days under El Niño conditions, increasing to 48 days under La Niña conditions, with similar values in northern spring. This difference is due to faster eastward propagation of the MJO convective anomalies through the Maritime Continent and western Pacific during El Niño, consistent with theoretical arguments concerning equatorial wave speeds.

The analysis is extended back to 1950 by using an alternative definition of the MJO based on just the zonal wind component of the Wheeler and Hendon indices. A rupture in the amplitude of the MJO is found in 1975, which is at the same time as the well-known rupture in the ENSO time series that has been associated with the Pacific decadal oscillation. The mean amplitude of the MJO is $16 \%$ larger in the postrupture (1976-2005) compared to the prerupture (1950-75) period. Before the 1975 rupture, the amplitude of the MJO is maximum (minimum) under El Niño (La Niña) conditions during northern winter, and minimum (maximum) under El Niño (La Niña) conditions during northern summer. After the rupture, this relationship disappears. When the MJO-ENSO relationship is analyzed using all-year-round data, or a shorter dataset (as in some previous studies), no relationship is found.
\end{abstract}

\section{Introduction}

The Madden-Julian oscillation (MJO; Madden and Julian 1994; Zhang 2005) is the dominant mode of atmospheric variability on intraseasonal time scales. It consists primarily of large-scale (approximately 1000 $\mathrm{km}$ across) deep convective tropical rainfall anomalies that propagate slowly eastward from the Indian Ocean, through the Maritime Continent of Indonesia, and into the western Pacific, where they decay around the date line. The time taken for one such MJO event is typically around 40 days, but it is more generally comprised between 30 and 60 days.

Corresponding author address: Benjamin Pohl, Centre de Recherches de Climatologie, 6 Boulevard Gabriel, F-21000 Dijon, France.

E-mail: benjamin.pohl@u-bourgogne.fr
The MJO shows a marked seasonality in its spatial extent. The core region of the oscillation is located at the low latitudes (between the equator and $15^{\circ}$ ) in the summer hemisphere (Goulet and Duvel 2000; Roundy and Frank 2004; Zhang and Dong 2004). During solstitial seasons it was shown that the MJO strongly interacts with the Asian (Yasunari 1980, 1981), Australian (Hendon and Liebmann 1990a,b), and African (Matthews 2004) monsoon systems. The intrinsic amplitude of the intraseasonal signal and the period of the MJO were first thought to be independent of the annual cycle (Anderson et al. 1984), but a significant peak in the MJO intensity during January-March was later found by Salby and Hendon (1994).

There is also significant year-to-year variability in the MJO. On interannual time scales, El Niño-Southern Oscillation (ENSO) is the most energetic mode of global atmospheric variability in the Tropics, and has at-

DOI: $10.1175 / J C L I 4230.1$ 
tracted a large number of studies since its discovery by Sir Gilbert Walker in the 1920s, and Bjerknes' works in the 1960s. In particular, recent years (since 1977) exhibit a warming in the Pacific basin, which was more recently explained as the most recent switch to the positive phase of the Pacific decadal oscillation (PDO; Mantua et al. 1997; Zhang et al. 1997; Deser et al. 2004; Wu et al. 2003, 2005). Concomitantly, stronger El Niño events were recorded (An et al. 2005).

Previous studies have shown that the overall amplitude of MJO activity did not appear to be directly affected by the presence of El Niño or La Niña (Slingo et al. 1999; Kessler 2001). However, the spatial envelope of MJO activity extends farther east than usual during El Niño conditions, beyond the date line into the central Pacific, associated with the warmer sea surface temperatures (SSTs) there (Anyamba and Weare 1995; Fink and Speth 1997; Vincent et al. 1998; Kessler 2001). Lagged relationships were also recently discovered between MJO activity in spring and the state of El Niño in subsequent autumn/winter seasons (Hendon et al. 2007). This tends to assess that warm conditions in the eastern Pacific could be initiated by the intraseasonal oscillation, through an eastward propagation of the warm pool and a development of surface westerly anomalies in the zonal wind.

In this paper we reexamine the relationship between the MJO and ENSO, using longer datasets (back to 1950) than have been previously analyzed, and focus on the shift in ENSO behavior in the mid-1970s that coincided with the switch in sign of the PDO. Section 2 presents the data used for the study. Section 3 defines the MJO cycle. The effects of ENSO on MJO lifetime are discussed in section 4 , and those on the amplitude of the MJO signal in section 5. The results are summarized and discussed in section 6 .

\section{Data}

Daily mean zonal wind data at 200 and $850 \mathrm{hPa}$ on a global $2.5^{\circ}$ latitude-longitude grid were extracted from the National Centers for Environmental PredictionNational Center for Atmospheric Research (NCEPNCAR) reanalysis (Kalnay et al. 1996) for the period from 1 January 1950 to 31 December 2005. Zonal wind is a class A ("most reliable") reanalysis variable, which is an important factor here because the time domain investigated precedes the satellite era.

Monthly mean SST data on a global $1^{\circ}$ latitudelongitude grid were obtained from the Met Office's Hadley Centre Sea Ice and SST dataset (HadISST) dataset (Rayner et al. 2003) for the same period. An ENSO Niño-4 index was created by averaging the SST data over the area of $5^{\circ} \mathrm{N}-5^{\circ} \mathrm{S}, 160^{\circ} \mathrm{E}-150^{\circ} \mathrm{W}$.
The gridded daily mean outgoing longwave radiation (OLR) dataset from the NOAA polar-orbiting satellites (Liebmann and Smith 1996) was used as a proxy for tropical convection and rainfall, as in many previous MJO studies (e.g., Matthews 2000). These were available on a global $2.5^{\circ}$ latitude-longitude grid for the period from 1 June 1974 to 31 December 2005.

\section{Defining the MJO}

\section{a. MJO life cycle}

In the interests of promoting a standard notation for the MJO and to avoid yet another definition of it, we use the MJO indices of Wheeler and Hendon (2004, hereafter WH04). The indices are the principal component (PC) time series of the two leading empirical orthogonal functions (EOFs) of combined daily mean tropical (averaged $15^{\circ} \mathrm{N}-15^{\circ} \mathrm{S}$ ) 850 - and $200-\mathrm{hPa}$ zonal wind and OLR anomalies. WH04 subtracted the annual cycle and the low-frequency variability associated with ENSO before calculating the EOFs. The indices were designed to be used in real time and to capture both the northern winter and summer MJO and are available from the Australian Bureau of Meteorology. The indices, denoted real-time multivariate MJO (RMM) 1 and RMM2, are in quadrature and describe the large-scale, eastward-propagating convective and circulation anomalies associated with the MJO. The evolution of the MJO can be concisely visualized in a twodimensional phase-space diagram, with RMM1 and RMM2 as the horizontal and vertical Cartesian axes, respectively. For example, in the 4-month period from 1 December 1987 to 1 April 1988, there were approximately $2.5 \mathrm{MJO}$ events, shown by the approximate 2.5 orbits in an anticlockwise direction around the origin in this phase space (Fig. 1). A polar coordinate representation can also be used (Matthews 2000) in this phase space, where $A$ is the amplitude $(A>0)$ and $\alpha$ is the phase angle $(0<\alpha<2 \pi)$. WH04 divide the MJO into eight phases, with phase 1 being the portion of phase space with phase angle between $\pi$ and $5 \pi / 4$, phase 2 being the portion of phase space with phase angle between $5 \pi / 4$ and $3 \pi / 2$, etc. (Fig. 1).

The use of this phase notation, rather than using fixed time lags, allows for individual MJO events with different periods (i.e., between approximately 30 and 60 days) to be composited easily. Prior to compositing, the annual cycle is removed from the data, which is then passed through a 20-75-day Butterworth filter. The MJO can be said to begin in phase 8 , when negative OLR anomalies (active convection) first appear in the western Indian Ocean basin (Fig. 2h), and then develop and slowly migrate eastward to the central Indian 


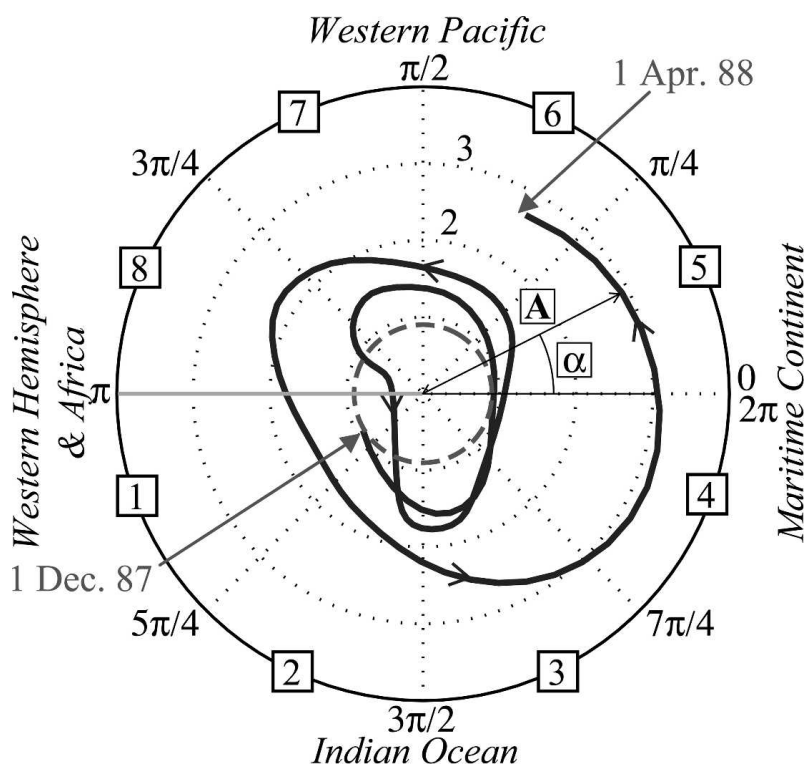

FIG. 1. Two-dimensional phase-space representation of the MJO for the period of 1 Dec 1987-1 Apr 1988. The horizontal and vertical axes are the RMM1 and RMM2 anomalies, respectively. The phase angle $\alpha$ is shown around the circular border. The eight phases (1-8) of the MJO and the approximate locations of the MJO-associated convective clusters are labeled, following WH04. The dashed circle at $A=0.9$ indicates the threshold used here for defining individual $\mathrm{MJO}$ events.

Ocean by phase 2 (Fig. 2b). Simultaneously, a region of positive OLR anomalies (a negative convective anomaly) is present over the western Pacific, consistent with the convective "dipole" phase of the MJO. At phase 4 the convective clusters are mainly located over the Maritime Continent (Fig. 2d), and then at phase 6 they have moved farther eastward to the western Pacific (Fig. 2f). By phase 8 the main region of enhanced convection is over the western hemisphere and Africa, with the beginning of the next cycle developing in the western Indian Ocean again (Fig. 2h). The main regions of enhanced convection at each phase of the MJO cycle are also indicated in Fig. 1.

\section{b. MJO lifetime}

The lifetime of each individual MJO event is now investigated. The onset of convection associated with the MJO takes place over the Indian Ocean (KemballCook and Weare 2001), at phase angle $\pi$ in the definition used here (Fig. 1). To calculate the lifetime of each MJO event the number of days separating two consecutive occurrences of phase angle $\pi$, that is, two consecutive onsets of convection, is calculated. An amplitude criterion is also applied to exclude the times during which the MJO is weak and is not detectable above the background noise. Only MJO cycles with a mean am- plitude greater than 0.9 (dashed circle, Fig. 1) and characterized by a clear and continuous eastward propagation (anticlockwise rotation of phase space vector) are included in the analysis here. The threshold of $A=0.9$ corresponds to the mean MJO amplitude averaged over the 1974-2004 period. There are 5026 days $(45.9 \%$ of the overall sample) that are over this threshold, and 157 full MJO events are finally retained in the period of 1974-2004, giving an average of 5.2 MJO events per year.

As expected, the mean lifetime is around 40 days (41.1 days), when averaged over the whole dataset. However, a nonnegligible seasonality is detected. Each individual MJO event is ascribed to the month in which its central day falls. The median lifetime varies from a minimum in December of 34.5 days to a maximum in September of 48 days (Fig. 3). In general, the MJO lifetime is shorter during equinoctial seasons (MarchMay and October-December) than during the summer and winter seasons. The statistical significance of this result is tested by an analysis of variance; we find that the MJO lifetime and the month of the year are not independent, at a significance level of $99.9 \%$. This result differs from that of Anderson et al. (1984) who used a shorter dataset; they are, however, fully confirmed by spectral analyses applied to the RMM indices for the four above-mentioned seasons of the year (not shown).

\section{Relationship between the MJO lifetime and ENSO}

\section{a. Correlations}

There is clearly variability in the spread of the lifetime of the $\mathrm{MJO}$, as indicated by the interquartile range and the full range of the MJO lifetimes for each month in Fig. 3, but there does not appear to be a coherent annual cycle to this variability. Here, we look for a year-to-year component of this variability by focusing on the major mode of interannual variability in the tropical atmosphere-ocean system: ENSO. First, the 3-month mean of the MJO lifetime is calculated for each of the 12 three-month "seasons": JanuaryFebruary-March (JFM), February-March-April (FMA), March-April-May (MAM), April-May-June (AMJ), May-June-July (MJJ), June-July-August (JJA), July-August-September (JAS), AugustSeptember-October (ASO), September-OctoberNovember (SON), October-November-December (OND), November-December-January (NDJ), and December-January-February (DJF). This was correlated with the 3-month mean Niño-4 index (Fig. 4). A mean of 3 months was chosen, because this was long 
(a) Phase 1: $\pi-5 \pi / 4$

(e) Phase 5: $0-\pi / 4$

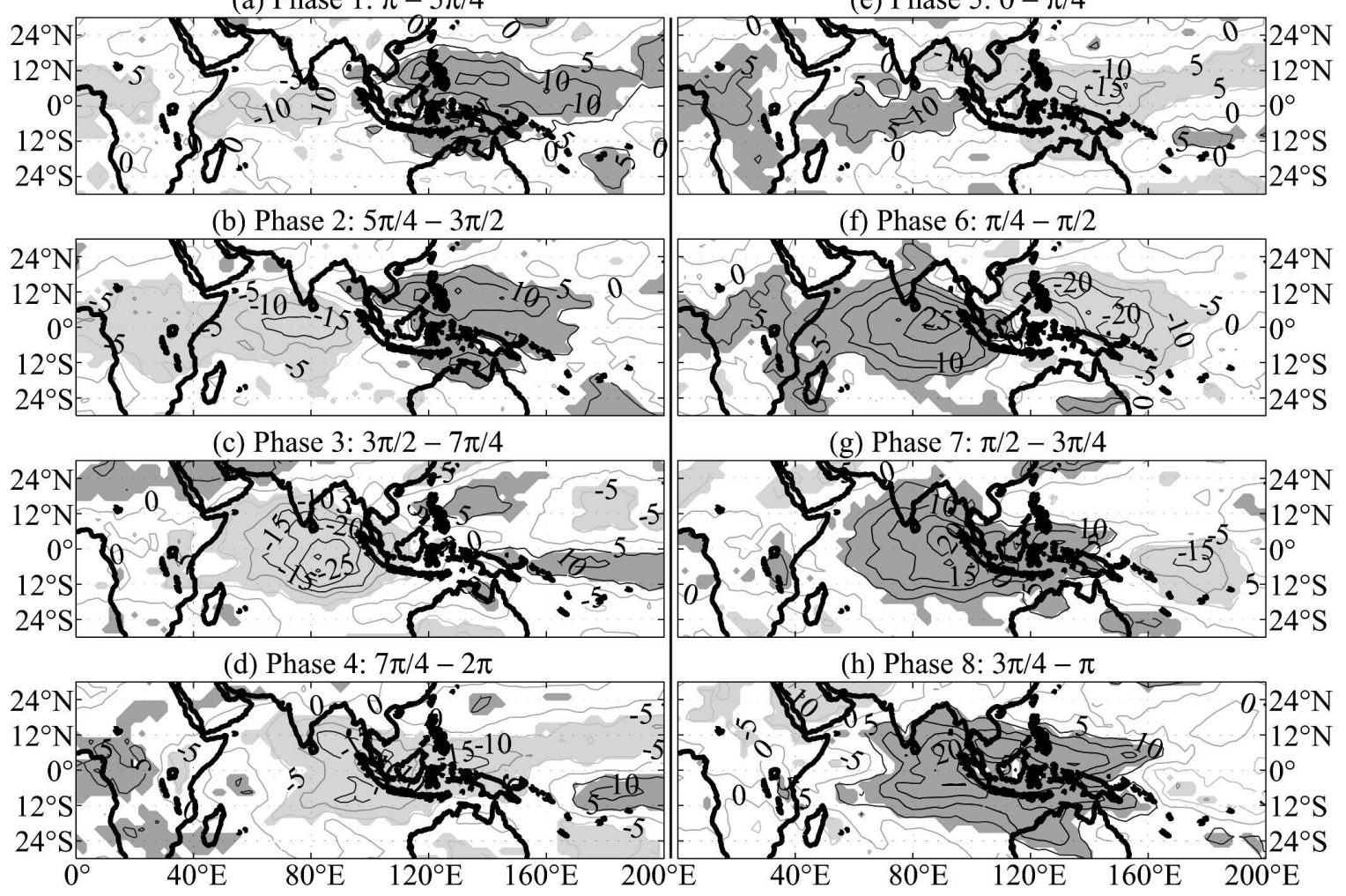

FIG. 2. Composite maps of OLR anomalies over the MJO cycle for each of the eight phases in the MJO cycle. Contour interval is 5 $\mathrm{W} \mathrm{m}^{-2}$. Dark (light) gray shading denotes positive (negative) anomalies that are locally statistically significant at the $95 \%$ level.

enough to include a sufficient number of MJO events in the sample to ensure statistical stability and short enough to resolve the seasonal dependence. The sensitivity of the results to the choice of the ENSO index will

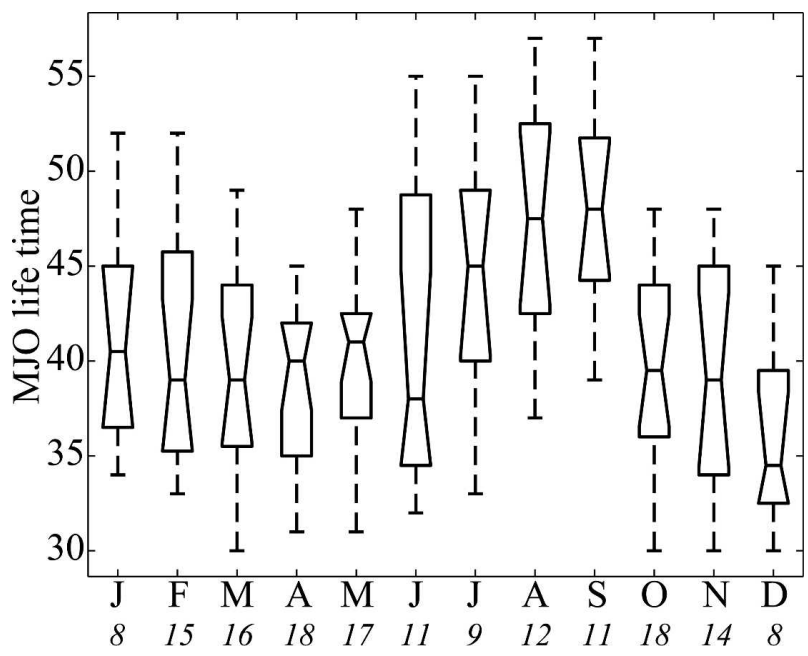

FIG. 3. Box-and-whisker plot of MJO lifetime (days) for each month of the year. The boxes have lines at the lower, median, and upper quartile values. The whiskers are lines extending from each end of the box to show the range of the data. The size of the sample used for the calculation is labeled under each month. be discussed below. The varying number of individual MJO events, and thus of degrees of freedom, was considered when testing the significance of the correlations.

The state of ENSO and the lifetime of the MJO are significantly correlated during the equinoctial seasons (February-May and September-December), such that the MJO period is longer in La Niña and shorter in El Niño, consistent with an analysis of limited station data by Gray (1988) and a local mode analysis of OLR by Goulet and Duvel (2000). However, the correlations are near zero for the northern winter period, and weakly positive for northern summer.

For the two seasons exhibiting the strongest correlations between the MJO lifetime and the Niño-4 index (MAM and OND), the correlation patterns between the MJO lifetime and gridded SST are displayed (Fig. $5)$. The number of MJO events included in each calculation is 51 and 40, respectively (Fig. 3). For both seasons negative correlations are found in the central and eastern Pacific basin, corroborating the results shown in Fig. 4. Also, positive correlations are found in the western Pacific, consistent with the well-known horseshoepatterned ENSO-associated SST anomalies (e.g., Zhang et al. 1997; Mantua et al. 1997; Wu et al. 2003). 

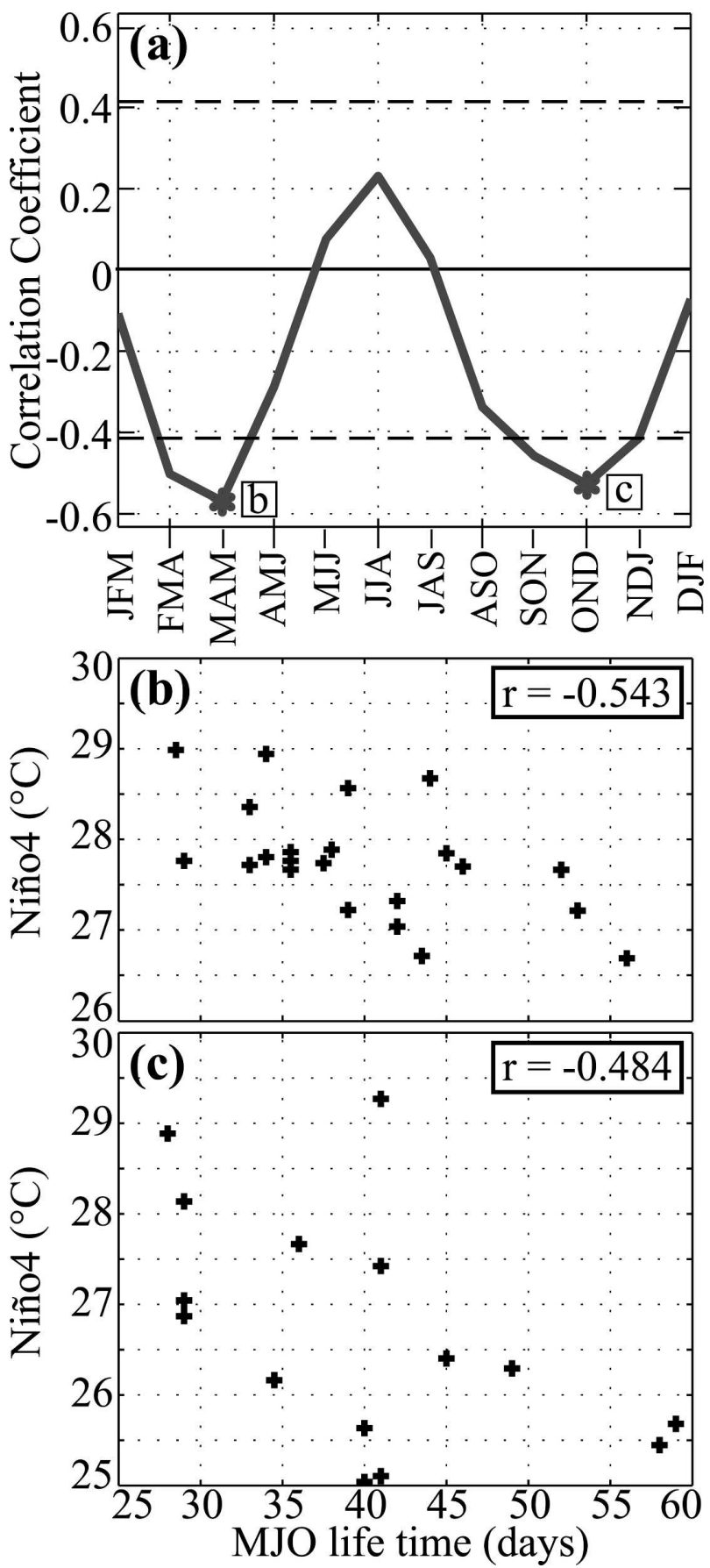

FIG. 4. (a) Simultaneous correlations between 3-month mean MJO lifetime and Niño-4 index for the period of 1974-2004. The $95 \%$ significance level is shown by the thick dashed lines. Scatterplots of 3-month mean MJO lifetime and Niño-4 index for (b) MAM and (c) OND.

The gridpoint correlations are slightly stronger in MAM than in OND, consistent with Fig. 4. This pattern also shows that the Niño- 4 area $\left(5^{\circ} \mathrm{S}-5^{\circ} \mathrm{N}, 160^{\circ}-150^{\circ} \mathrm{W}\right)$ is indeed located within the strongest teleconnection pockets: weaker (but still significant) results are also obtained with Niño-3 and, to a lesser extent, Niño-3.4 indexes. Localized pockets of significant correlations are also found in the Atlantic Ocean in MAM, and the Indian Ocean in OND.

\section{b. Details of changes in the MJO lifetime with ENSO}

Given that the MJO lifetime is longer during La Niña conditions (Figs. 4, 5) and that the zonal distance for the MJO convection to traverse is shorter (Vincent et al. 1998; Kessler 2001), then these two factors imply that the eastward propagation speed of the MJO must be slower during La Niña. To analyze this, the MJO cycle was further split into 16 phase bins (each with a phase length of $\pi / 8$ ), and the average time spent in each phase bin is shown in Fig. 6. The average lifetime of an individual MJO event is the sum of the time spent in each phase bin: 36.0 (46.8) days in El Niño (La Niña) conditions in MAM, and 32.4 (47.6) days in El Niño (La Niña) conditions in OND. These differences are statistically significant in a $t$ test at the $95 \%$ level.

Closer examination of Fig. 6 shows that the difference in the lifetime (or equivalently propagation speed) is concentrated in specific phases of the MJO cycle, rather than being spread evenly through it. For OND in particular (Fig. 6b), the quarter MJO cycle between $7 \pi / 4$ and $\pi / 4$ (phases $4 / 5$ ) only takes 7.5 days to complete in El Niño compared to 13.2 days in La Niña conditions. This part of the MJO cycle corresponds to the eastward propagation of the enhanced convection across the Maritime Continent (Figs. 1, 2). Similarly, the quarter MJO cycle between $3 \pi / 4$ and $5 \pi / 4$ (phases $8 / 1$ ) only takes 4.6 days to complete in El Niño compared to 11.4 days in La Niña conditions. This part of the MJO cycle corresponds to the eastward propagation of the reduced convection across the Maritime Continent. There is a similar, though less marked, behavior in MAM (Fig. 6a). The enhanced and suppressed MJO convective anomalies take a shorter time to propagate through the Maritime Continent-western Pacific sector in El Niño conditions compared to La Niña conditions.

\section{c. Mechanisms}

The propagation speed of the MJO under normal conditions shows large variations throughout its cycle. Over the "moist convective" regime of the warm pool (Indian Ocean through to the western Pacific) it is approximately 4-5 $\mathrm{m} \mathrm{s}^{-1}$, while over the "dry" regime of the eastern Pacific it is much faster, between 10 and 40 $\mathrm{m} \mathrm{s}^{-1}$, depending on which variable is considered (Salby and Hendon 1994; Bantzer and Wallace 1996; 


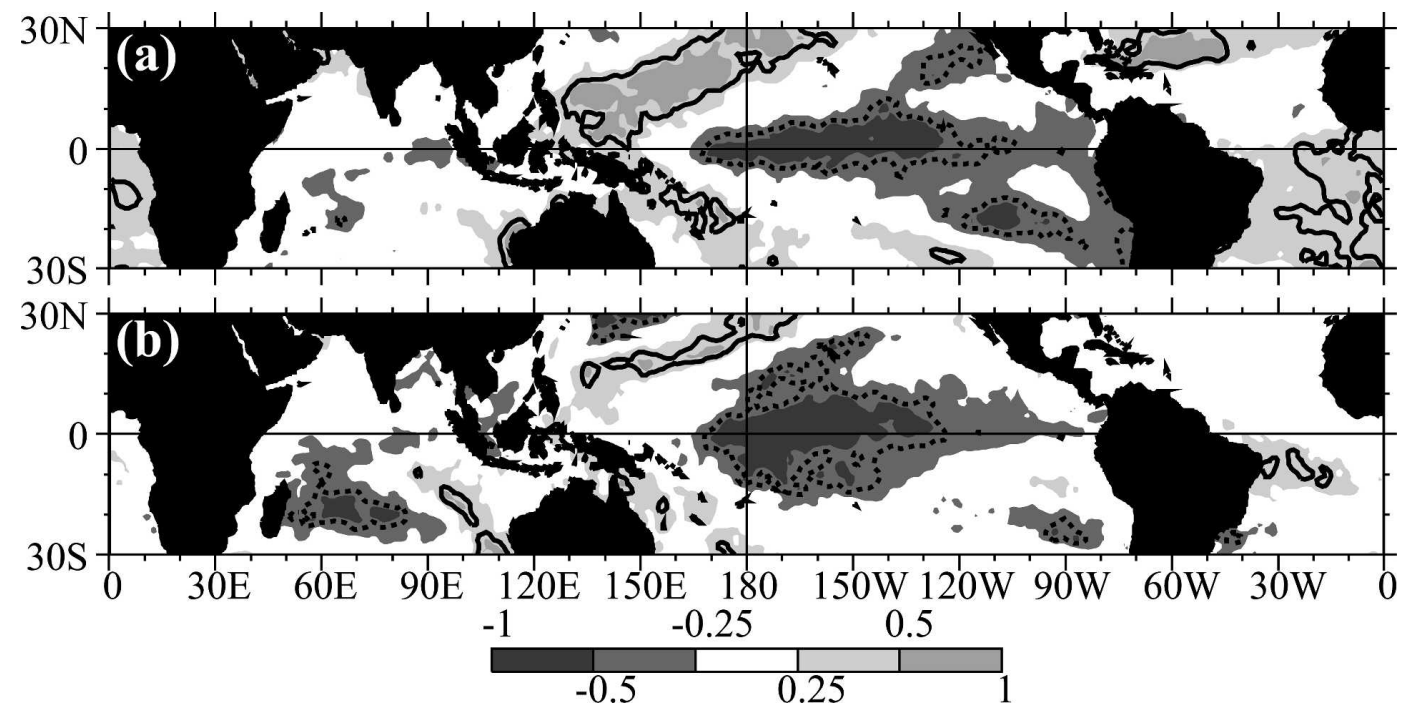

FIG. 5. Correlation pattern between 3-month mean lifetime of the MJO and the 3-month mean gridpoint SST for (a) MAM and (b) OND. See legend for shading. The solid (dashed) contour shows areas of negative (positive) correlations that are locally significant at the $95 \%$ level.

Matthews 2000). This has been explained as a change in the phase speed of the equatorial Kelvin wave component of the MJO. The MJO propagation speed approaches the theoretical speed of a dry Kelvin wave in the dry regime, whereas in the moist convective regime, the latent heat release in the ascending part of the wave partially offsets the adiabatic cooling of expansion, and therefore acts to decrease the effective static stability of the atmosphere, thus slowing the wave down (Gill 1982).

We hypothesize that the changes in the MJO propagation speed over the Maritime Continent-western Pacific sector between El Niño and La Niña conditions may be at least partially due to the same mechanism. During El Niño, conditions over this area are drier than normal, related to the suppression of mean convection there. Hence, there will be a weak "dry" regime over the sector, and the MJO would be expected to speed up there, as observed. However, other factors such as the mean zonal wind shear, and the longitudinal extent of the warm pool itself, may also be important. These observational results could be addressed by a set of numerical model experiments.

\section{Decadal change in the relationship between the MJO amplitude and ENSO}

As discussed in section 1, the amplitude of the MJO also exhibits strong variability on the seasonal, annual, and interannual time scales. However, no simultaneous significant correlations between the amplitude of MJO
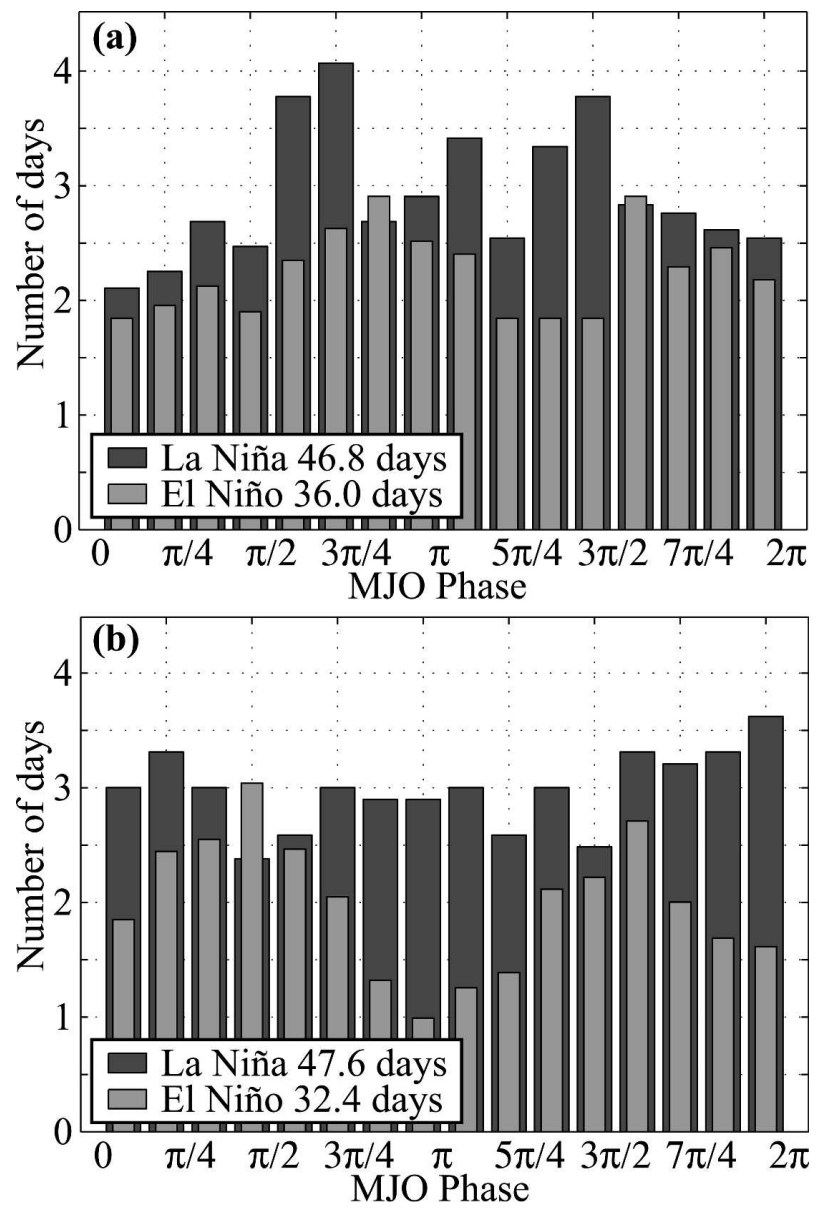

FIG. 6. Mean time (number of days) spent in each $1 / 16$ cycle MJO phase bin during El Niño (light gray) and La Niña (dark gray) conditions, for (a) MAM and (b) OND. 
activity and ENSO have been found to date (Anyamba and Weare 1995; Slingo et al. 1996; Slingo et al. 1999). Here, we explore the interdecadal variability of MJO activity, and reexamine the link between MJO activity and the state of ENSO, with a longer dataset that has been used before.

\section{a. Alternative definition of the MJO life cycle}

We would prefer to define the MJO based either on its convective signal using the OLR dataset, or, as in WH04 and the earlier part of this paper, on a combination of its dynamical and convective signals, because such a definition is most physically meaningful. However, because the satellite-measured OLR dataset began in 1974, we need an alternative definition of the MJO if we are to extend the analysis prior to this time. The reanalysis data, which extend back to 1948 , are the prime candidate. However, the reliability of the reanalysis in the presatellite era is questionable (Trenberth et al. 2001; Kanamitsu et al. 2002; Kinter et al. 2004), and caution must be exercised. The zonal wind field was chosen to define the MJO, because zonal wind is a class A ("most reliable") variable from the reanalysis (Kalnay et al. 1996) and the MJO signal in zonal wind is strong (Madden and Julian 1994; WH04; Zhang 2005).

For consistency with the results described above, we adopt the approach of WH04, but drop the OLR component. Hence, the alternative MJO cycle is based on an EOF analysis of combined tropical 850- and 200-hPa zonal winds. Data from 1 January 1948 to 31 December 2005 were used. As in WH04, the annual cycle was subtracted from the daily mean data; however, the EOF analysis was applied on the whole atmospheric fields between $15^{\circ} \mathrm{N}$ and $15^{\circ} \mathrm{S}$, and not on an equatorial average, in order to best capture the events that are not symmetrical around the equator (N.B., the results were insensitive to whether the equatorial averaging was carried out or not, not shown). The fields were also passed through a 20-75-day filter to remove high-frequency noise. The EOF analysis was based on the correlation matrix, and each grid point of the U850 and U200 fields was standardized over the 1950-2005 period after filtering. The filter removed the (real or artificial) longterm trends in the reanalyses (Kinter et al. 2004) for each grid point, as well as the interannual (and ENSO related) fluctuations in the zonal wind. The leading two EOFs describe $12.6 \%$ and $10.2 \%$ of the variance, respectively, and are separated from the following EOFs by a scree test. Kessler (2001), however, noted that the third PC, neglected in most papers, may also be associated with the MJO. To address this potential problem, Fig. 7 shows the results of cross-spectrum analyses be-
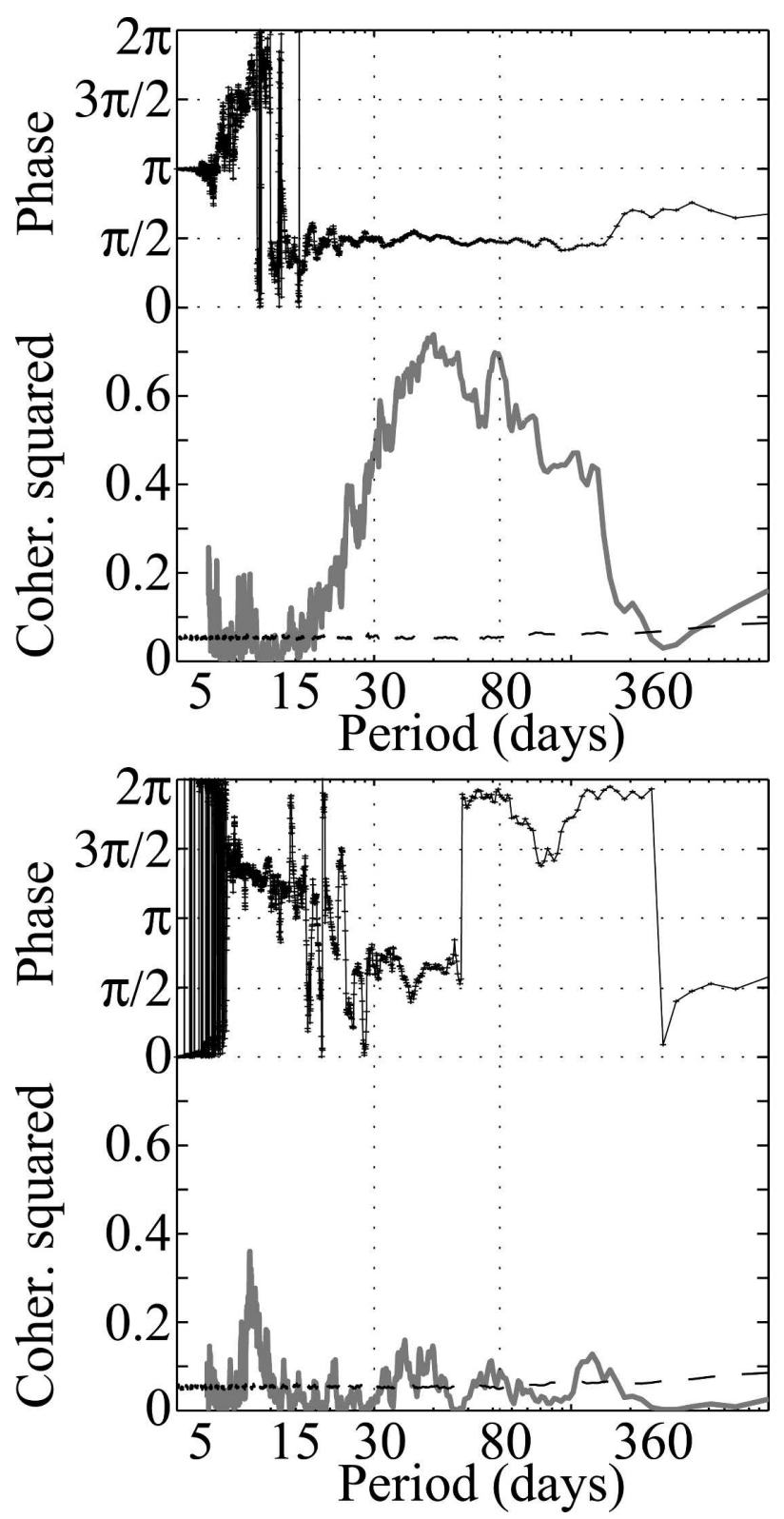

FIG. 7. Coherence squared and phase (radians) between (top) PC1 and PC2, and (bottom) PC1 and PC3. Dashed lines indicate 95\% confidence level according to 1000 random time series obtained as permutations of the original time series, and having the same lag-1 serial correlation.

tween PC1, PC2, and PC3. Both PC1 and PC2 are significantly related to each other at the time scales that are comprised of between 30 and 80 days, as for the WH04 indices (see their Fig. 3). For the phase, the constant $\pi / 2$ relationship means that PC1 leads PC2 by a quarter cycle, showing that they form a pair in quadrature. The coherence squared between PC1 and PC3 is much less at the intraseasonal (30-80 day) time scale, and is not significant. These results show that PC3 


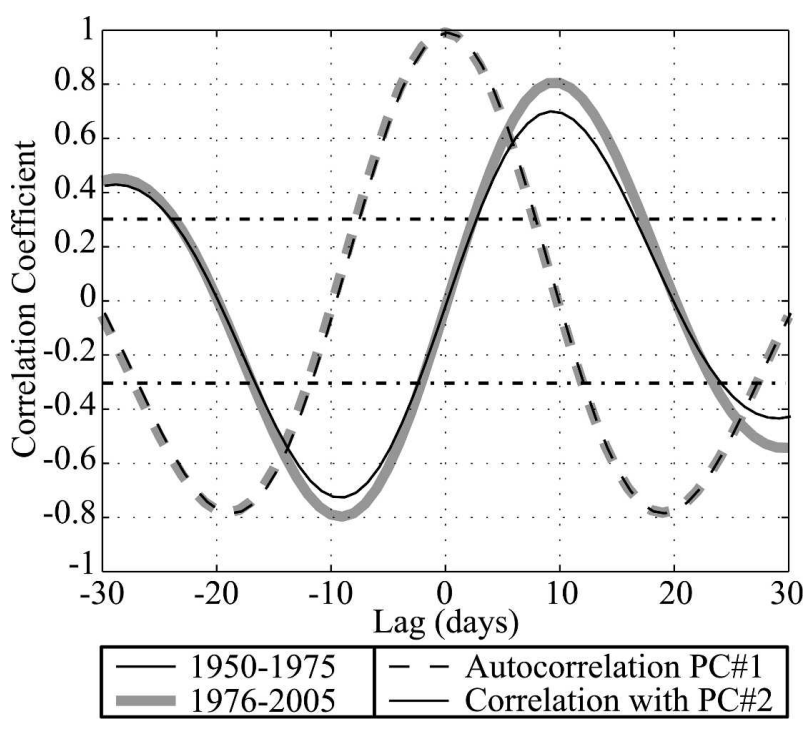

FIG. 8. Lag correlation between PC1 and PC2 of combined 850and 200-hPa zonal wind, for the periods of 1950-75 (black solid line) and 1976-2005 (gray solid line), and autocorrelation of PC1 for the periods of 1950-75 (black dashed line) and 1976-2005 (gray dashed line). Significance bounds at the 95\% level are shown as straight dash-dotted lines.

is statistically not associated with the MJO signal, such as that extracted by the pair (PC1, PC2).

The PC time series of the first two zonal wind EOFs are called $\mathrm{PC} 1$ and $\mathrm{PC} 2$, respectively. These are the alternative $\mathrm{MJO}$ indices to be compared with the RMM1 and RMM2 indices of WH04.

First, the ability of $\mathrm{PC} 1$ and $\mathrm{PC} 2$ to represent the MJO is examined. PC1 and PC2 are in quadrature (Fig. 7) in both the 1976-2005 satellite era (black solid line in Fig. 8) and the 1950-1975 presatellite era (gray solid line in Fig. 8). The autocorrelation function of PC1 is also essentially indistinguishable between the satellite era (black dashed line in Fig. 8) and the presatellite era (gray dashed line in Fig. 8), confirming that the reanalysis zonal wind in the presatellite era can be used to define the MJO.

The zonal wind-based $\mathrm{MJO}$ indices $(\mathrm{PC} 1, \mathrm{PC} 2)$ are compared with the combined zonal wind- and convective-based WH04 indices (RMM1, RMM2) in Fig. 9. Note that the two sets of indices can only be compared for the 1974-2005 period, when the OLR data became available. Examples are given for MAM and OND, which are the two seasons for which the use of WH04 indices was detailed in section 3. Similar results are obtained for the other seasons (not shown). For the MAM season, PC1 and RMM1 are simultaneously correlated, with a lag-zero correlation coefficient of 0.97 , while PC2 lags by a quarter cycle (Fig. 9a). Similarly, PC2 and RMM2 are very highly simultaneously corre- lated in MAM (Fig. 9b). The correlations are equally high in OND (Figs. 9c,d). The interannual variability of the MJO amplitude is very similar between the two sets of indices; scatterplots of the seasonal mean amplitude of the RMM indices and the PC indices are also very highly correlated, with correlation coefficients of 0.97 and 0.94 in MAM and OND, respectively. Hence, the zonal wind-based $\mathrm{MJO}$ indices (PC1, PC2) give an almost identical representation of the $\mathrm{MJO}$, in terms of both phase and amplitude, as the zonal wind- and convection-based WH04 indices during their common (satellite era) time period.

\section{b. Extraction of the boreal summer intraseasonal oscillation}

The WH04- and the zonal wind-based indices both use data averaged from $15^{\circ} \mathrm{S}$ to $15^{\circ} \mathrm{N}$. This is ideal for extracting the MJO signal during northern winter, when the MJO anomalies are approximately symmetrical about the equator, but may be less than optimal for identifying the MJO during northern summer, when the $\mathrm{MJO}$ anomalies are strongest north of the equator. In addition, the EOFs on which the indices are based are calculated using year-round data, again potentially favoring the northern winter/spring season when the MJO is strongest. However, WH04 showed that their indices do indeed capture the MJO well during northern summer. In this section, we confirm their result and also show that the zonal wind indices efficiently extract the MJO during northern summer.

For brevity, the MJO cycle has been compressed into four phases here, compared to the eight shown in Fig. 2. The MJO cycle for July-September, calculated using the WH04 indices based on all-year-round data, is shown in Figs. 10a-d. The northward propagation of convective anomalies from the equator to the Asian continent can be clearly seen (e.g., Yasunari 1979; Knutson and Weickmann 1987), confirming the suitability of these indices for analyzing the MJO during northern summer (WH04). The MJO cycle for JulySeptember calculated using the NCEP zonal wind data only, based on all-year-round data, is shown in Figs. $10 \mathrm{e}-\mathrm{h}$. Although the amplitude of the OLR anomalies is weaker, because the index is not OLR based, the overall anomaly pattern is very similar to the cycle in Figs. 10a-d, confirming that the zonal wind-based index is also suitable for extracting the MJO signal in northern summer. Finally, the MJO cycle for JulySeptember based on EOFs of July-September zonal wind data only, is shown in Figs. 10i-l. Again, this is similar to the previous MJO cycles, confirming that the construction of the indices is not sensitive to season. 


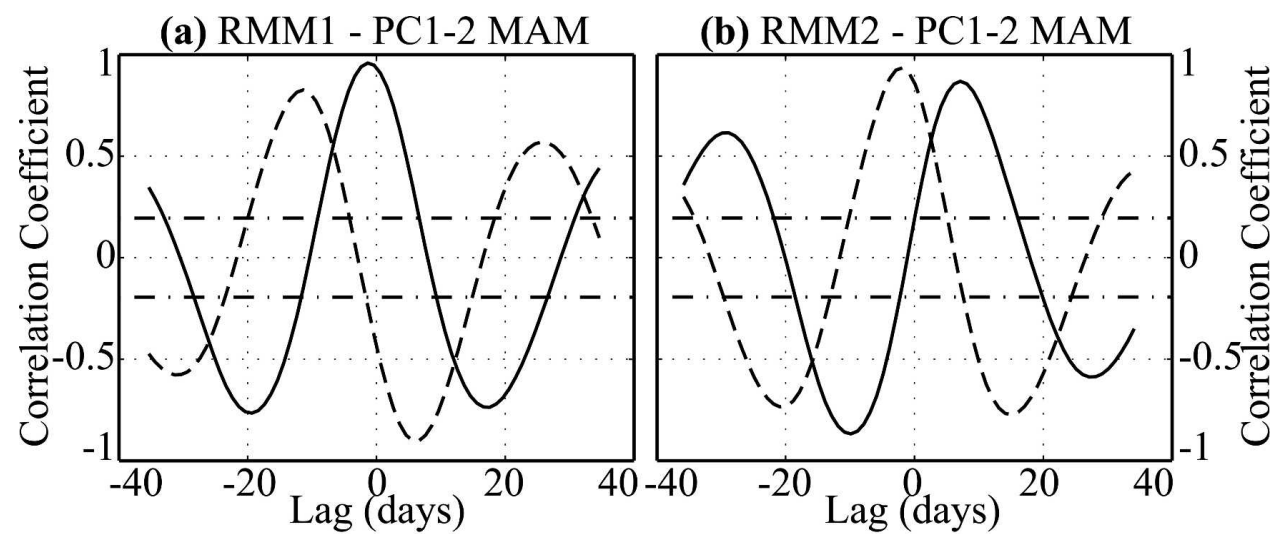

(c) RMM1 - PC1-2 OND

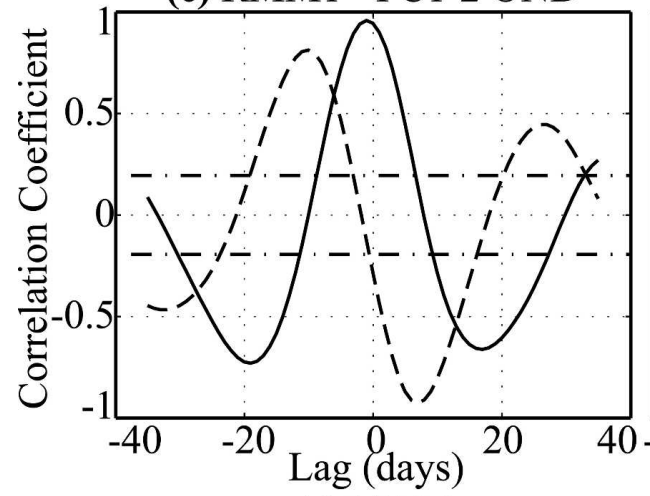

(d) RMM2 - PC1-2 OND

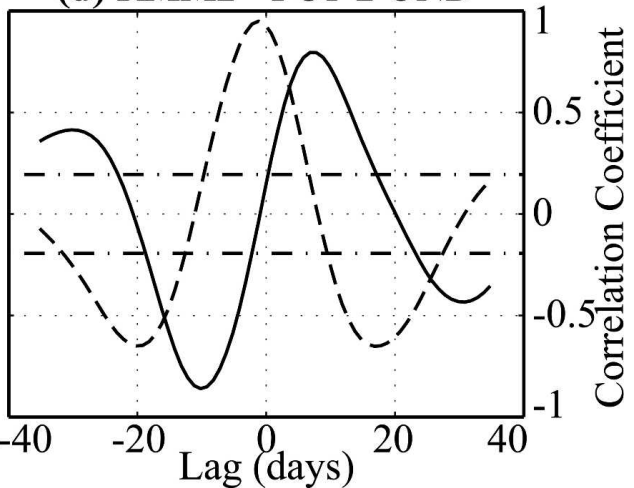

(e) MAM

(f) OND

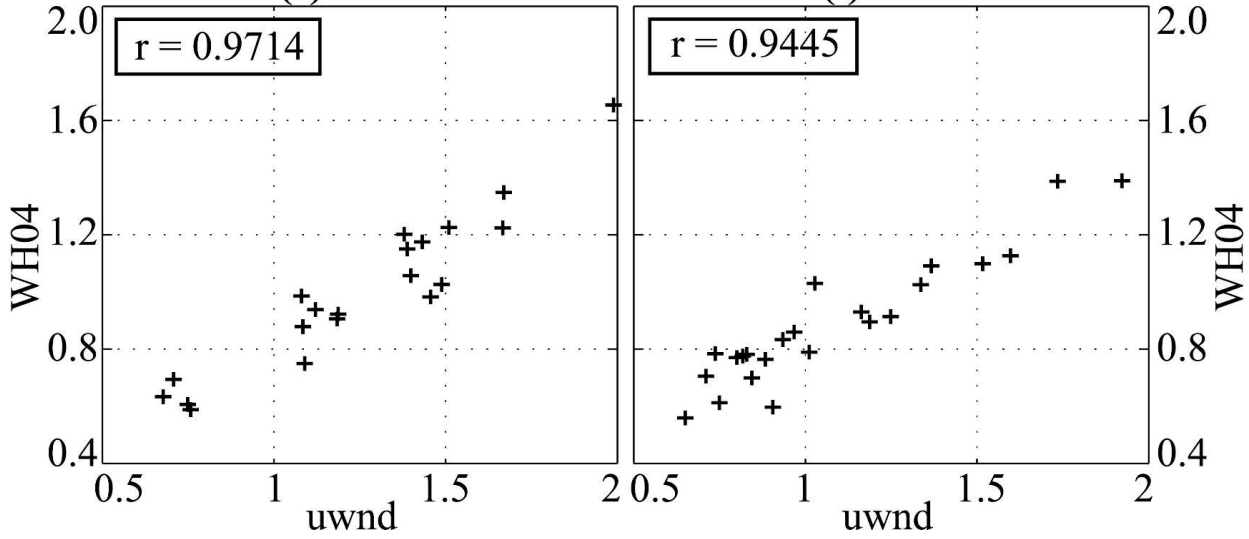

FIG. 9. Lag correlations between WH04's (a) RMM1 and (b) RMM2 and 200- and 850-hPa zonal wind PC1 (solid line) and PC2 (dashed line) of combined 850- and 200-hPa zonal wind for MAM. Significance bounds at the $95 \%$ level are shown as straight dashed lines. (c), (d) Same as (a), (b), but for OND. Scatterplots of seasonal mean MJO amplitude as calculated from zonal wind indices ( $x$ axis) vs WH04 indices ( $y$ axis) for (e) MAM and (f) OND of 1974-2005.

\section{c. Climatology of the MJO}

The seasonal cycle of the MJO amplitude (Fig. 11) also exhibits strong common features between the two sets of indices. The peak in MJO activity in both indices is in the MAM season, which is a result slightly different from that obtained by Salby and Hendon (1994), who found a maximum in the JFM period. A comparison between the two periods provided by the zonal wind indices indicates an interdecadal increase in the amplitude of the MJO, which will be discussed in section $5 \mathrm{~d}$.

\section{d. Decadal change in the ENSO-MJO behavior}

This section investigates the evolution of MJO activity since the 1950s, using the zonal wind-based MJO indices. The interdecadal evolution of the annual mean 

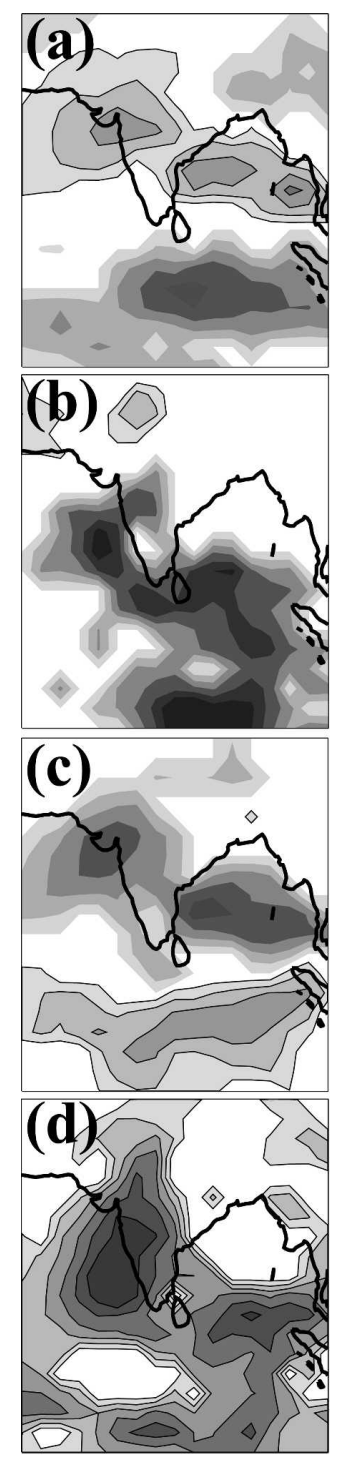
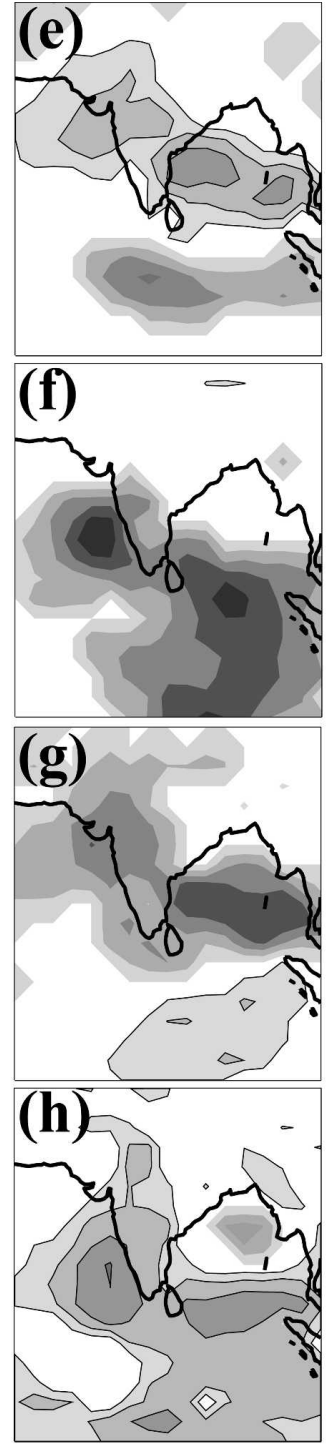
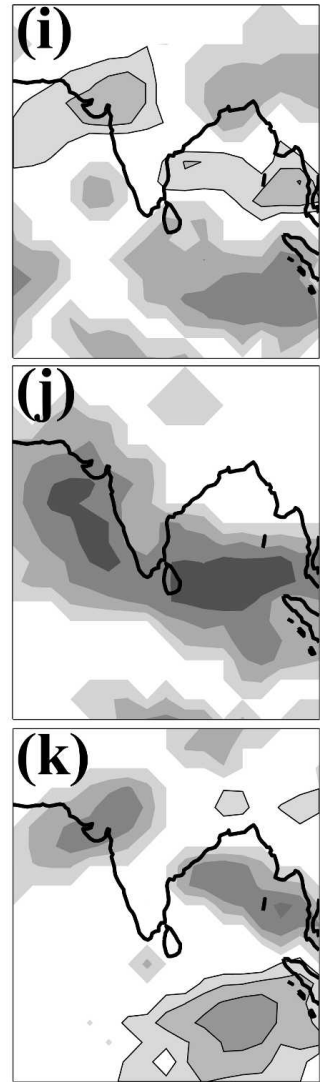

(I)

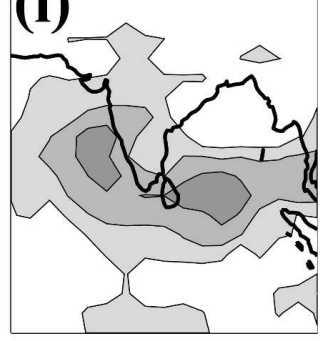

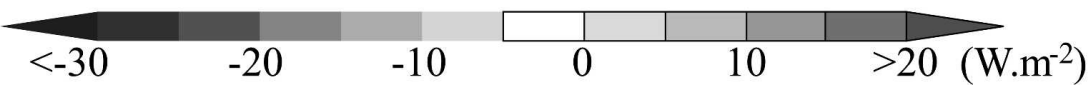

FIG. 10. OLR composite anomalies for each quarter of the MJO cycle for the July-September season, based on (a)-(d) the WH04 indices, (e)-(h) NCEP zonal wind indices from all-year-round data, and (i)-(l) NCEP zonal wind indices from July-September data only. Shading interval is $10 \mathrm{~W} \mathrm{~m}^{-2}$. Positive anomalies are also contoured with an interval of $10 \mathrm{~W} \mathrm{~m}^{-2}$. Areas that are not statistically significant are shaded white.

MJO amplitude shows an increasing trend (Fig. 12a) that is statistically significant at the $95 \%$ level in a Spearman test. In addition a Pettitt test (Pettitt 1979) is used to find ruptures in the time series. One is found in 1973, which is significant at the $95 \%$ level (Fig. 12b). The annual mean Niño-4 index also exhibits a significant rupture, in 1977, consistent with Mantua et al. (1997), Zhang et al. (1997), Deser et al. (2004), or Wu et al. (2003, 2005). For the remainder of this study the data are thus analyzed separately for two periods: 1950-75 and 1976-2005.
The MJO amplitude increases between 1950-75 and 1976-2005 over its entire annual cycle by 16\% (Fig. 11). Closer examination reveals that the increase is mainly concentrated from March to June, with a secondary increase in August and October. Such trends could be due to an improving quality of the reanalyses over the period, possibly related to an increasing number of atmospheric observations and satellite measurements. The other hypothesis involves a real climatic trend that could relate to the strong global warming observed over the second half of the twentieth century. For the re- 


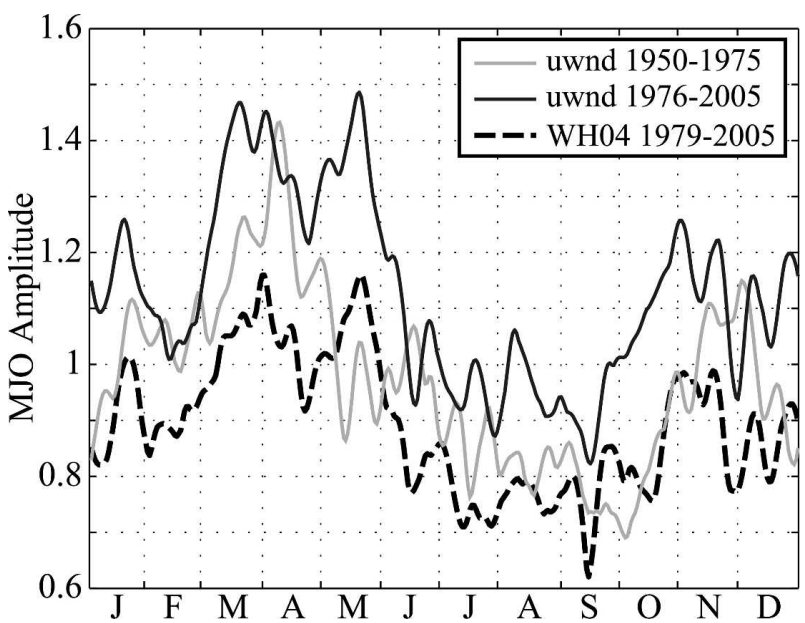

FIG. 11. Seasonal cycle of MJO amplitude from the WH04 indices (1974-2005) and the zonal wind indices (1950-75 and 19762005).

mainder of the work, the linear trends in the Niño-4 and MJO amplitude time series have been removed.

Following Hendon et al. (2007), Fig. 13 depicts the annual cycle of the correlations between the 3-month mean MJO amplitude and the corresponding Niño-4 index for the 1950-75 and 1976-2005 periods. High amplitudes on their own do not identify MJO activity, and the correct phase relation between the two indices is also required to show that there is eastward propagation. However, in practice it was found that there was

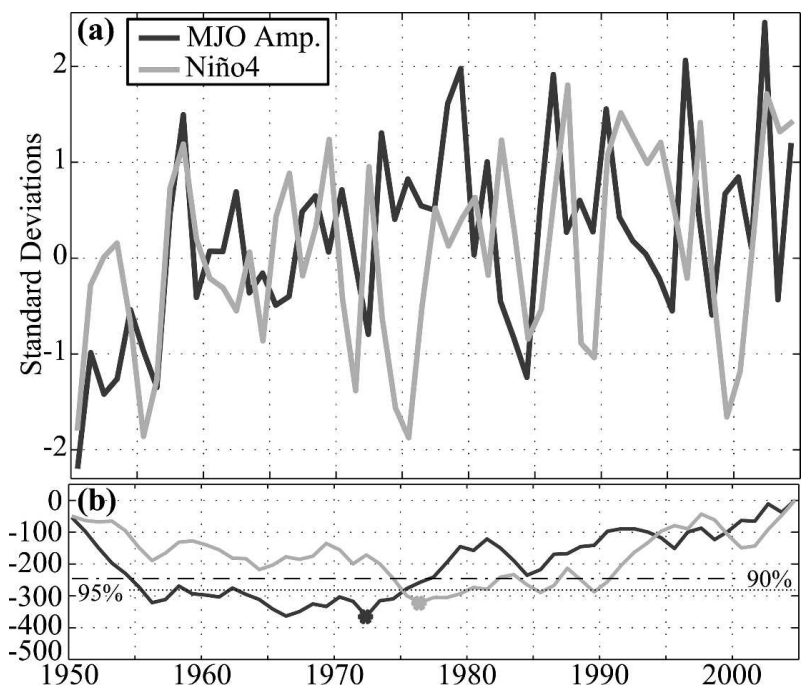

FIG. 12. (a) Annual mean MJO amplitude (dark gray line) and Niño-4 index (light gray line). The time series are standardized to allow for comparison. (b) Pettitt test statistic for the time series in (a). The $90 \%$ and $95 \%$ significance levels are shown by horizontal lines.

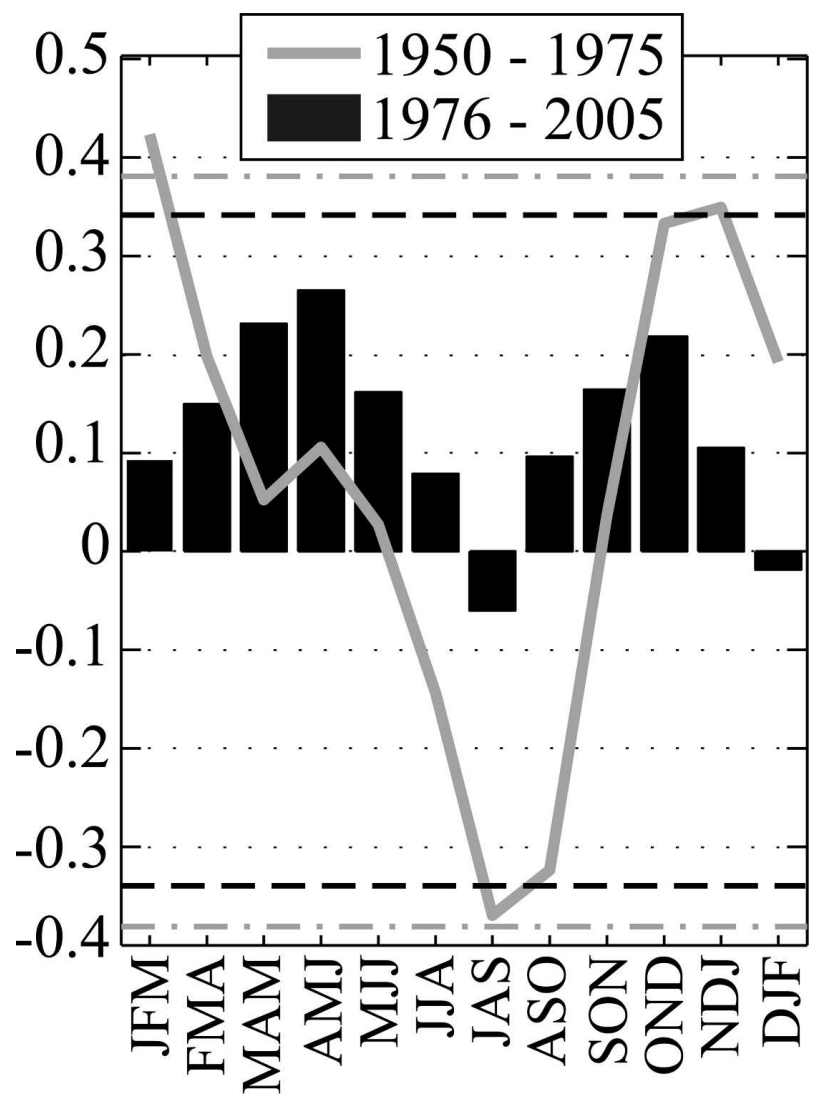

FIG. 13. Annual cycle of the teleconnections between 3-month mean Niño-4 index and MJO activity for 1950-75 (solid line) and 1976-2005 (bars). The 95\% significance level for each period is shown by the dashed line.

always eastward propagation when the index amplitudes were high.

The correlation is positive in northern autumn, winter, and spring, indicating enhanced MJO activity during El Niño conditions, which is intuitively consistent with the two positive trends observed in Fig. 12. In the earlier 1950-75 period, the positive correlation is largest and significant at the $95 \%$ level, during the northern winter, when El Niño events tend to be at their strongest. There are significant negative correlations during the northern summer in the 1950-75 period, indicating enhanced MJO activity during La Niña conditions. The correlations during the later 1976-2005 period are much weaker and are not significant at any time of year, consistent with Fink and Speth (1997) and Slingo et al. (1999). This change in the ENSO-MJO relationship between winter and summer indicates that the relationship should not be analyzed using year-round data, consistent with recent work by Hendon et al. (2007). Scatterplots of the Niño-4 index and MJO amplitude mean values (not shown) confirm these results. The MJO am- 


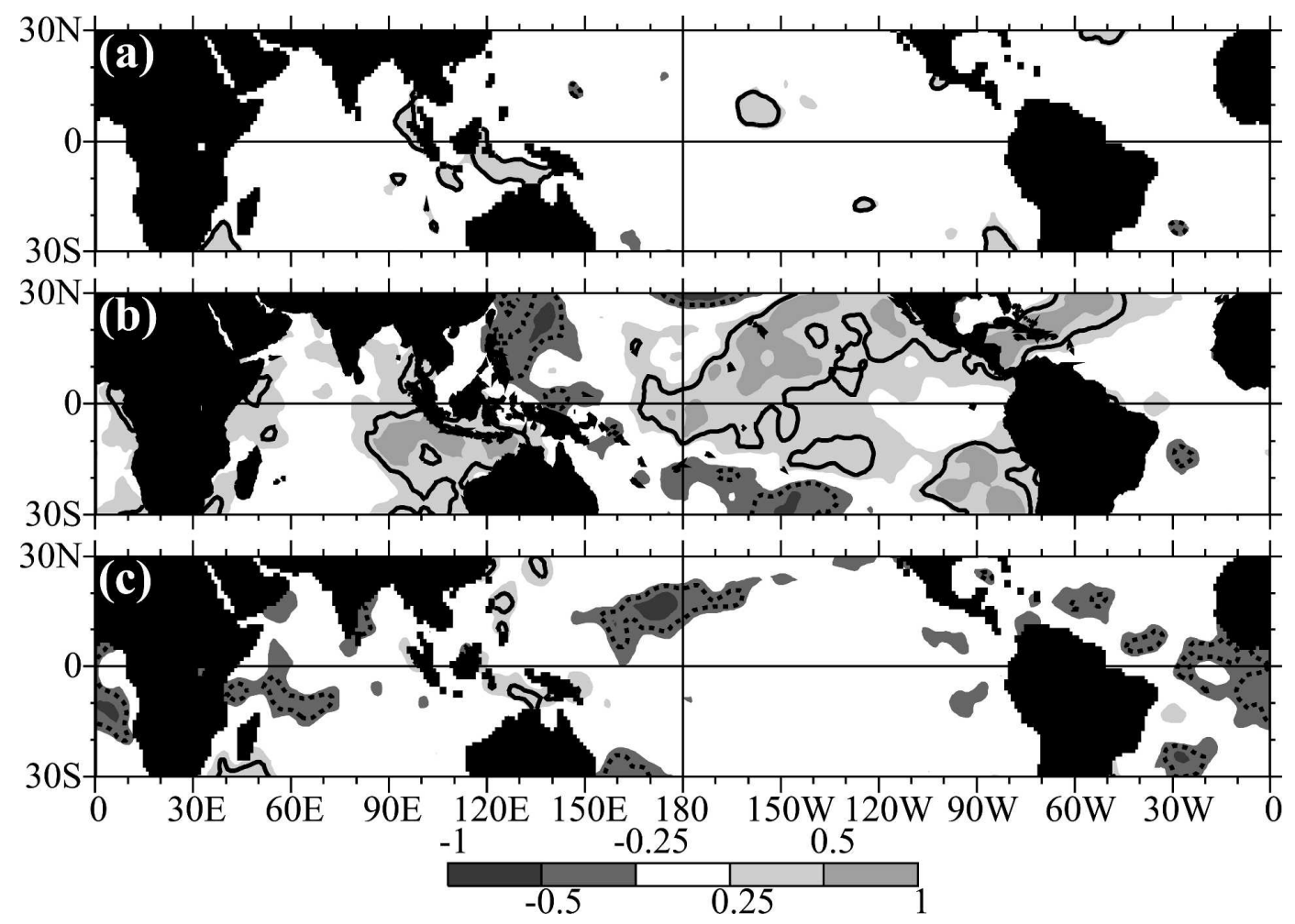

FIG. 14. Correlations pattern between seasonal mean MJO amplitude in NDJ and the gridpoint mean SST for (a) 1950-2000, (b) 1950-75, and (c) 1976-2005. The solid (dashed) contour shows areas of negative (positive) correlation that are significant at the $95 \%$ level.

plitude tends to be consistently higher during El Niño (positive correlations) during 1950-75, and the significance is not due to a small number of extreme values. For the 1976-2005 period, the MJO amplitude and Niño-4 index appear statistically independent.

The correlation values in Fig. 13 may hide stronger teleconnection patterns, because they relate specifically to the Niño-4 region in the central Pacific. The correlations between the MJO amplitude and the corresponding 3-month-averaged gridded SST are therefore computed for each 3-month season. The correlation maps are most coherent for northern winter (see Fig. 14, for NDJ) and summer (see Fig. 15, for JAS).

For NDJ, there are large areas of significant correlations for the earlier 1950-75 period (Fig. 14b). The negative correlations in the western Pacific (horseshoe pattern) and the positive correlations in the eastern $\mathrm{Pa}$ cific are consistent with El Niño. Areas of significant positive correlations are also found in the Indian and Atlantic basins. However, in the later 1976-2005 period, the relationships dramatically weaken and are only statistically significant in a small region in the western Pacific (Fig. 14c), consistent with Hendon et al. (1999). When the whole 1950-2005 period is analyzed together, there are virtually no significant correlations between the MJO amplitude and the state of ENSO (Fig. 14a).

In the northern summer season (JAS), the correlation pattern is reversed compared to that in winter, consistent with Fig. 13. In the earlier 1950-75 period (Fig. 15b), there are large areas of positive correlation over the western Pacific and negative correlation over the eastern Pacific, consistent with enhanced MJO activity during La Niña events. Scatterplots (not shown) indicate that these high correlation values are enhanced by an extreme year (1973), which had anomalously high MJO activity and cold SST in the Niño-4 area. However, even when this year is removed, the teleconnections with the SST remain highly significant over the eastern Pacific basin. Partial correlations in the presence of the multivariate ENSO index (MEI) and Southern Oscillation index (SOI) confirm that the significance of the relationships, found for 1950-75, is indeed related to ENSO. However, the correlation values (with or without 1973) are not as robust as for NDJ, and the spatial configurations are not as reminiscent of ENSO-induced SST anomalies. Once again, the correlation map (Fig. 15c) and scatterplots (not shown) for the later 1976-2005 period (Fig. 15c) do not show a significant relationship between MJO activity and the 


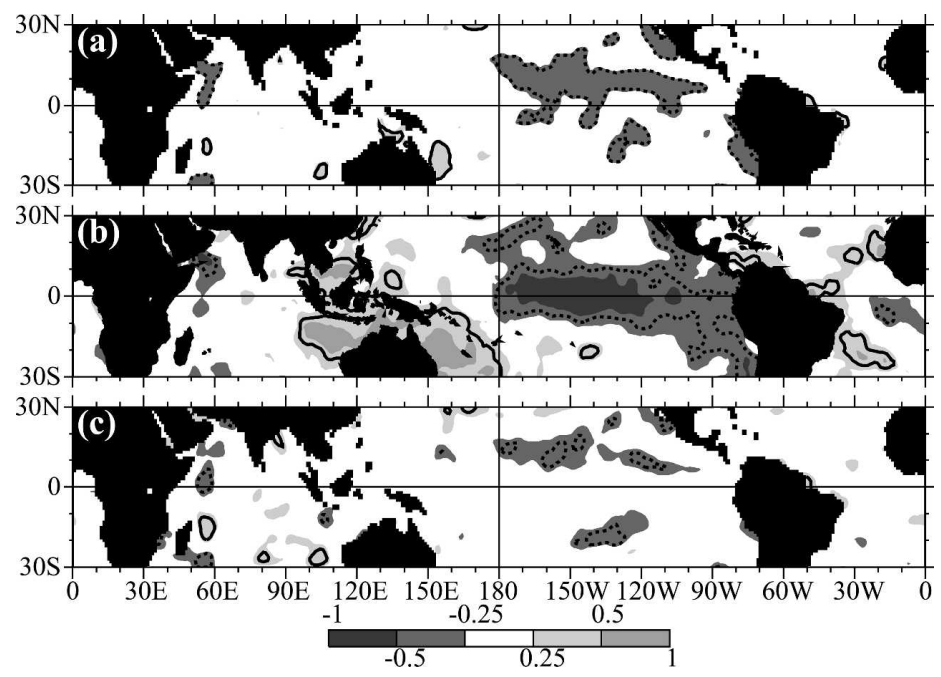

FIG. 15. Same as in Fig. 13, but for JAS.

state of ENSO. The correlations over the whole 19502005 period are also only weakly significant (Fig. 15a).

Figure 16 shows lagged correlations between 3-month means of the MJO amplitude and Niño-4 in- dex. The thick diagonal line is the zero-lag line. Correlations in the region above and to the left of this are associated with anomalous MJO activity lagging anomalous ENSO activity, and correlations in the re- (a) 1950 - 1975

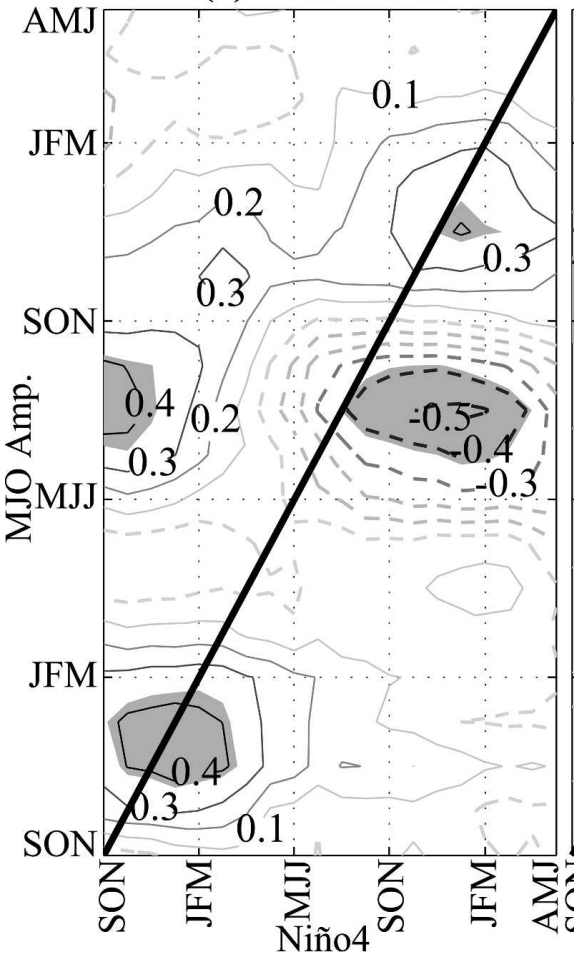

(b) 1976 - 2005

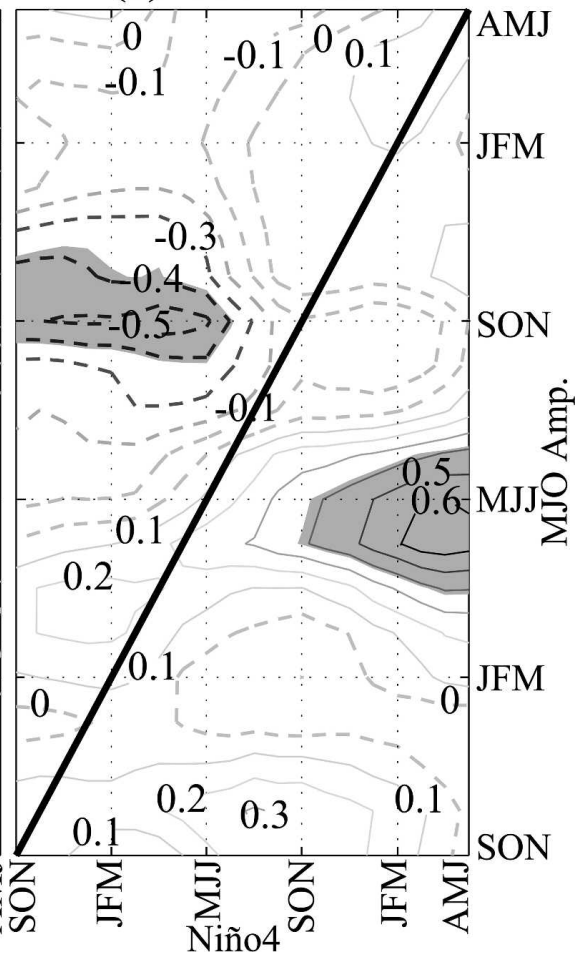

FIG. 16. Lagged correlations between the 3-month mean MJO amplitude and 3-month mean Niño-4 index, for (a) 1950-75 and (b) 1976-2005. Contour interval is 0.1, and negative contours are dashed. Shading denotes significant correlations at the $95 \%$ level, from a BravaisPearson test. Zero lag is shown by the thick diagonal line. 
gion below and to the right of this are associated with anomalous MJO activity leading anomalous ENSO activity.

During the earlier 1950-75 period, significant synchronous (zero lag) correlations of positive (negative) sign are found during the northern winter (summer) seasons (Fig. 16a), consistent with the results shown in Figs. 13, 14, and 15. However, the negative synchronous correlations in summer are part of a wider lagged relationship, where reduced (enhanced) MJO activity in summer is associated with an El Niño (La Niña) the following winter.

The relationships in the later 1976-2005 period (Fig. 16b) are very different. Zhang and Gottschalck (2002) also described a sudden change (in 1979) in the lagged ENSO-MJO relationship, and their results for the 1980-99 period are consistent with those exposed below. Significant positive correlations are found between northern spring MJO amplitude and the Niño-4 index during the subsequent autumn, winter, and spring seasons. Hendon et al. (2007) also pointed out similar results and deduced that enhanced MJO activity in spring is associated with an eastward-expanded warm pool in the Pacific and with westerly surface zonal wind anomalies. These conditions are known to be favorable to the development of an El Niño event. In addition, we find here that there is also a region of strong negative lagged correlations, such that El Niño (La Niña) conditions in autumn, winter, and spring are associated with reduced (increased) MJO activity in the following autumn.

Hence, there are two major conclusions from this section: (i) interannual fluctuations in MJO activity are not purely stochastic, in contrast to studies that used shorter datasets (e.g., Slingo et al. 1999); and (ii) a sudden change in the MJO-ENSO relationship occurred abruptly in the mid-1970s.

The period between 1975 and 1978 is already known as a key period with regard to ENSO activity (Wang 1995; Zhang et al. 1997; Deser et al. 2004; An et al. 2005). The three first papers identified the years 197677 as a major rupture with regard to the global ocean temperature and to the intensity of the El Niño events. An et al. (2005) more recently established that the ENSO cycle exhibits a stronger nonlinearity since the late 1970s. The question that remains unresolved is whether these changes, so far detected for the only interannual time scale, indeed play a significant role in the recent degradation of the El Niño-MJO teleconnections.

\section{Summary and conclusions}

This study focuses on two major characteristics of the MJO-its lifetime (linked to its phase speed) and its amplitude. To that end, the daily MJO indices developed by Wheeler and Hendon (2004) were used for the 1974-2005 period.

It is first found that, contrary to the results of Anderson et al. (1984), the lifetime of the MJO shows a sharp seasonality during the period. The MJO has a significantly shorter lifetime during the equinoctial seasons (March-May and October-December) than at other times of the year. Interestingly, the interannual fluctuations in the MJO period during these same seasons are also related to the state of El Niño. Significantly shorter (longer) lifetimes are found during warm (cold) conditions in the eastern Pacific, consistent with Gray (1988) and Goulet and Duvel (2000). The zonal distance to traverse for convection is higher however, because the MJO signal extends farther east, beyond the date line, when warm conditions occur in the Pacific (Fink and Speth 1997; Vincent et al. 1998; Kessler 2001). It is therefore concluded that the phase speed of the MJO is significantly higher during El Niño. The changes in the propagation of the MJO between El Niño and La Niña are mainly concentrated over the Maritime Continent of Indonesia, which is an area that experiences drier conditions than usual during El Niño. Our hypothesis is that these interannual changes in the humidity of the air masses affect the MJO propagation over the region, which would be consistent with theoretical arguments concerning equatorial wave speeds. The fact that significant relationships with El Niño are only found for those two seasons of the year, during which the ITCZ is at the very low latitudes, reinforces this statement.

Previous studies have concluded that the statistical relationship between the amplitude of the intraseasonal signal and the phase of El Niño were very weak (e.g., Slingo et al. 1999; Kessler 2001). During the last 50 yr, however, El Niño activity has been marked by strong interdecadal fluctuations. A major rupture was identified in 1976-77 in a large number of studies (e.g., Zhang et al. 1997; Deser et al. 2004; Wu et al. 2003, 2005; An et al. 2005) and was interpreted as a change in the phase of the Pacific decadal oscillation. The modulation of the MJO-El Niño relationships at the interdecadal time scale was therefore examined. It necessitated the computation of MJO indices extending back to 1950. For consistency, they were calculated using the same methodology as that of Wheeler and Hendon (2004), but are only based on the 850- and 200-hPa zonal wind fields derived from the NCEP-NCAR reanalyses (Kalnay et al. 1996).

A first statement concerns the long-term evolution of the annual mean MJO activity. A significant positive trend is detected between 1950 and 2005, and an increase of $16 \%$ is found between the pre- and the post- 
rupture periods. The physical reality of these relationships is questioned. These results could be due to the improving quality of the reanalyses over the period (Trenberth et al. 2001; Zhang and Gottschalck 2002; Kinter et al. 2004). The coincidence with the first satellite measurements remains particularly curious. However, the mid-1970s rupture was depicted in many other datasets and seems quite consistent from one study to another; therefore, the increase in the intraseasonal activity could also denote real interdecadal climatic fluctuations. The implication of the warming of the tropical ocean and atmosphere is also subject to interrogations.

Beyond these long-term trends, the interannual variability of the MJO signal has also changed at the mid1970s rupture. It was shown that before this key date, higher MJO activity was statistically recorded when warm events prevailed in the Pacific during boreal winter (November-March). Reverse teleconnections were recorded during boreal summer (July-September). Both relationships disappear for the latest $30 \mathrm{yr}$. These relationships had not been depicted in previous studies (Fink and Speth 1997; Vincent et al. 1998; Anyamba and Weare 1995; Slingo et al. 1999), because the opposite sign of the correlations between winter and summer cancel when averaged over the annual cycle. In addition, many works focused on the two or three latest decades during which satellite data were available; but these years also correspond to the period during which the teleconnection patterns show barely significant results.

The physical causes behind these interdecadal fluctuations in the MJO-ENSO relationships remain subject to uncertainties. Other studies (Slingo et al. 1999; Zhang and Gottschalck 2002) already suggested substantial changes in the MJO activity before and after the 1970s, but did not establish the exact nature of the physical processes. The relative briefness of reliable atmospheric measures is undoubtedly at the origin of our incomplete understanding of such long-term climatic fluctuations. Nonetheless, these results all lead to similar conclusions: under the climate conditions of the last $30 \mathrm{yr}$ (positive phase of the Pacific decadal oscillation) there appears to be some predictability in the development of an El Niño event based on the MJO activity during the preceding spring (Hendon et al. 2007). However, ENSO indicators cannot be used as predictors for interannual fluctuations in the MJO signal. The next switch of the interdecadal Pacific oscillation may possibly force us to renew these conclusions.

Acknowledgments. The MEI and SOI, OLR field, and NCEP-NCAR reanalyses were provided through the NOAA Climate Diagnostics Center (information online at http://www.cdc.noaa.gov). The HadISST data were provided by the Met Office (information online at http://www.badc.nerc.ac.uk/data/hadisst/). The Wheeler and Hendon MJO indices were provided through the Australian Bureau of Meteorology (information online at http://www.bom.gov.au).

\section{REFERENCES}

An, S. I., W. W. Hsieh, and F. F. Jin, 2005: A nonlinear analysis of the ENSO cycle and its interdecadal changes. J. Climate, 18, 3229-3239.

Anderson, J. R., D. E. Stevens, and P. R. Julian, 1984: Temporal variations of the tropical 40-50 day oscillation. Mon. Wea. Rev., 112, 2431-2438.

Anyamba, E. K., and B. C. Weare, 1995: Temporal variability of the 40-50-day oscillation in tropical convection. Int. J. Climatol., 15, 379-402.

Bantzer, C. H., and J. M. Wallace, 1996: Intraseasonal variability in tropical mean temperature and precipitation and their relation to the tropical 40-50-day oscillation. J. Atmos. Sci., 53, 3032-3045.

Deser, C., A. S. Phillips, and J. W. Hurrell, 2004: Pacific interdecadal climate variability: Linkages between the Tropics and the North Pacific during boreal winter since 1900. J. Climate, 17, 3109-3124.

Fink, A., and P. Speth, 1997: Some potential forcing mechanisms of the year-to-year variability of the tropical convection and its intraseasonal (25-70 day) variability. Int. J. Climatol., 17, $1513-1534$

Gill, A. E., 1982: Studies of moisture effects in simple atmospheric models: The stable case. Geophys. Astrophys. Fluid Dyn., 19, $119-152$.

Goulet, L., and J.-P. Duvel, 2000: A new approach to detect and characterize intermittent atmospheric oscillations: Application to the intraseasonal oscillations. J. Atmos. Sci., 57, 23972416.

Gray, B. M., 1988: Seasonal frequency variations in the 40-50 day oscillation. J. Climatol., 8, 511-519.

Hendon, H. H., and B. Liebmann, 1990a: A composite study of onset of the Australian summer monsoon. J. Atmos. Sci., 47, 2227-2239.

— , and — 1990b: The intraseasonal (30-50 day) oscillation of the Australian summer monsoon. J. Atmos. Sci., 47, 29092923.

_ C. Chang, and J. D. Glick, 1999: Interannual variation of the Madden-Julian oscillation during austral summer. J. Climate, 12, 2538-2550.

—, M. C. Wheeler, and C. Zhang, 2007: Seasonal dependence of the MJO-ENSO relationship. J. Climate, 20, 531-543.

Kalnay, E., and Coauthors, 1996: The NCEP/NCAR 40-Year Reanalyses Project. Bull. Amer. Meteor. Soc., 77, 437-471.

Kanamitsu, M., W. Ebisuzaki, J. Woollen, S.-K. Yang, J. J. Hnilo, M. Fiorino, and G. L. Potter, 2002: NCEP-DOE AMIP-II reanalysis (R-2). Bull. Amer. Meteor. Soc., 83, 1631-1643.

Kemball-Cook, S. R., and B. C. Weare, 2001: The onset of convection in the Madden-Julian oscillation. J. Climate, 14, 780793.

Kessler, W. S., 2001: EOF representation of the Madden-Julian oscillation and its connection with ENSO. J. Climate, 14, 3055-3061.

Kinter, J. L., M. J. Fennessy, V. Krishnamurthy, and L. Marx, 
2004: An evaluation of the apparent interdecadal shift in the tropical divergent circulation in the NCEP-NCAR reanalysis. J. Climate, 17, 349-361.

Knutson, T. R., and K. M. Weickmann, 1987: 30-60 day atmospheric oscillations: Composite life cycles of convection and circulation anomalies. Mon. Wea. Rev., 115, 1407-1436.

Liebmann, B., and C. A. Smith, 1996: Description of a complete (interpolated) outgoing longwave radiation dataset. Bull. Amer. Meteor. Soc., 77, 1275-1277.

Madden, R. A., and P. R. Julian, 1994: Observations of the 4050-day tropical oscillation-A review. Mon. Wea. Rev., 122, 814-837.

Mantua, N. J., S. R. Hare, Y. Zhang, J. M. Wallace, and R. C. Francis, 1997: A Pacific interdecadal climate oscillation with impacts on salmon production. Bull. Amer. Meteor. Soc., 78, 1069-1079.

Matthews, A. J., 2000: Propagating mechanisms for the MaddenJulian oscillation. Quart. J. Roy. Meteor. Soc., 126, 2637-2652.

_ , 2004: Intraseasonal variability over tropical Africa during northern summer. J. Climate, 17, 2427-2440.

Pettitt, A. N., 1979: A nonparametric approach to the changepoint problem. Appl. Stat., 28, 126-135.

Rayner, N. A., D. E. Parker, E. B. Horton, C. K. Folland, L. V. Alexander, D. P. Rowell, E. C. Kent, and A. Kaplan, 2003: Global analyses of sea surface temperature, sea ice, and night marine air temperature since the late nineteenth century. $J$. Geophys. Res., 108, 4407, doi:10.1029/2002JD002670.

Roundy, P. E., and W. M. Frank, 2004: A climatology of waves in the equatorial region. J. Atmos. Sci., 61, 2105-2132.

Salby, M. L., and H. H. Hendon, 1994: Intraseasonal behavior of clouds, temperature, and motion in the Tropics. J. Atmos. Sci., 51, 2207-2224.

Slingo, J., and Coauthors, 1996: Intraseasonal oscillations in 15 atmospheric general circulation models: Results from an AMIP diagnostic subproject. Climate Dyn., 12, 325-357.

, D. P. Rowell, K. R. Sperber, and F. Nortley, 1999: On the predictability of the interannual behaviour of the Madden-
Julian Oscillation and its relationship with El Niño. Quart. J. Roy. Meteor. Soc., 125, 583-609.

Trenberth, K. E., D. P. Stepaniak, and J. W. Hurrell, 2001: Quality of reanalyses in the Tropics. J. Climate, 14, 1499-1510.

Vincent, D. G., A. Fink, J. M. Schrage, and P. Speth, 1998: Highand low-frequency intraseasonal variance of OLR on annual and ENSO timescales. J. Climate, 11, 968-986.

Wang, B., 1995: Interdecadal changes in El Niño onset in the last four decades. J. Climate, 8, 267-285.

Wheeler, M. C., and H. H. Hendon, 2004: An all-season real-time multivariate MJO index: Development of an index for monitoring and prediction. Mon. Wea. Rev., 132, 1917-1932.

Wu, L., Z. Liu, R. Gallimore, R. Jacob, D. Lee, and Y. Zhong, 2003: Pacific decadal variability: The tropical Pacific mode and the North Pacific mode. J. Climate, 16, 1101-1120.

— D. E. Lee, and Z. Liu, 2005: The 1976/77 North Pacific climate regime shift: The role of subtropical ocean adjustment and coupled ocean-atmosphere feedbacks. J. Climate, 18, 5125-5140.

Yasunari, T., 1979: Cloudiness fluctuations associated with the Northern Hemisphere summer monsoon. J. Meteor. Soc. Japan, 57, 227-242.

_ 1980: A quasi-stationary appearance of the 30-40-day period in cloudiness fluctuations during the summer monsoon over India. J. Meteor. Soc. Japan, 58, 223-229.

_- 1981: Structure of an Indian summer monsoon system with around 40-day period. J. Meteor. Soc. Japan, 59, 336-354.

Zhang, C., 2005: Madden-Julian Oscillation. Rev. Geophys., 43, RG2003, doi:10.1029/2004RG000158.

— , and J. Gottschalck, 2002: SST anomalies of ENSO and the Madden-Julian oscillation in the equatorial Pacific. J. Climate, 15, 2429-2445.

- and M. Dong, 2004: Seasonality in the Madden-Julian oscillation. J. Climate, 17, 3169-3180.

Zhang, Y., J. M. Wallace, and D. S. Battisti, 1997: ENSO-like interdecadal variability: 1900-93. J. Climate, 10, 1004-1020. 